\title{
On Cultivation Countermeasure of the Rebound Grabbing Ability of Players in the Basketball Training
}

\author{
Zhen Tan \\ NanChang Institute of Science and Technology,Nanchang,330108
}

Keyword: Basketball player; Grabbing; Rebound grabbing ability

\begin{abstract}
The rebound grabbing ability is one of the remarkable symbols which are used to evaluate the quality of a basketball team. Long-term science, the rebound grabbing ability of basketball players has always been the weak link in the skills and tactics system in our country, especially the post players of our country are weaker than the post players of the basketball teams in Europe and America. So it is the major issue our basketball game now faces to improve the rebound grabbing ability of our basketball players, especially the rebound grabbing ability of the post players. The rebound grabbing ability of basketball players generally include the abilities in four aspects of the sense of grabbing rebound, the body confrontation capability, the skills of grabbing rebound and the rebound technical cooperation. This paper attempts to analyse and inquire into the above three aspects in order to provide the majority of coaches and players with the theoretical basis in their training of grabbing rebound.
\end{abstract}

\section{Introduction}

With the development of the professional basketball worldwide, the basketball in the world is developing rapidly towards high speed, strong confrontation and higher intellectual level. In the basketball match, grabbing the rebound is an important mean of getting the possession of the basketball, the key of the conversion of offense and defense and the decision of the game, and one of the symbols which judge the quality of one player and the whole team. It is an important feature of modern basketball to fiercely grab and control the rebound. Grabbing the defensive rebound can help a team to get rid of the continuous attack threat from the offensive team, rapidly change from the defensive to the offensive and organize a counterattack. At the same time, grabbing the defensive rebound also can increase the concerns of the outside offensive players of shooting and reduce the percentage of his shot. Grabbing the offensive rebound can help a team to carry out the continuous attack to the defensive basket, increase the number of attack and scoring chances, increase the confidence of the player shot, boost the morale of players and increase the percentage shots. So the further improvement of the rebound grabbing ability of players has important theoretical significance and application value for the results improvement of Chinese ens basketball in the world tournaments and the development of Chinese basketball.

\section{Definition of the Basketball Consciousness}

The basketball consciousness can consider as one basketball player's abilities to control and govern his awareness and action self-consciously and in purpose based on the learning of the experience of old players of dealing with the complex situations and the full reading of the play. The basketball consciousness is regarded as the most precious essence of one basketball player which is gradually cultivated and improved in the long term of players' basketball learning, training and matches. One basketball player with stronger basketball consciousness must have stronger strain capacity. Many players has no strong basketball consciousness, those specific behavioral performances are as follows: (1)low change from the defensive to the offensive, often make the opponent out of his sight by turning his back to the opponent; (2)does not immediately catch up with and defend the opponent with full speed after lossing the opponent, too high center of gravity of players when defending; (3)lack of the awareness of compensation defense when help defense is carried out, only see the ball but the opponent; (4)fails to carry out the cooperation of players and the basketball when a quick 
attack is carried out because of the awareness of waiting the ball; (5)lack of the coordination consciousness in position offensive; (6) lack of the ability to control the pace of the game, and pay more attention to the high speed; (7)Lack of the blunt rebound consciousness and the rush-position consciousness when grabbing the rebound.

\section{Essential Factors of Grabbing Rebound of Basketball Player}

Observation and Judgement. "One who knows his own strength and that of the enemy is invincible in battle". One player should fully observe the defensive trend and has a right understanding for the movements of his teammates and the play of the whole team when grabbing the offensive rebound. When a shot is missed, there are some rules between the rebound direction and the landing point of the basketball and the distance, angle, strength and radian of the shot, only mastering the basic rules of shot, one player can make right decision, move to grab the basketball in time and seize the favorable position.

Seizing the Favorable Position. Seizing the favorable position is the key link of grabbing the rebound. There are generally three means of seizing the favorable position. The first mean is roundabout starting that one offensive player should quickly start running in time in a roundabout way to seize the relatively favorable or better position in accordance with his judgement for the rebound of the ball and the defensive situation of the opponent. The second mean is seizing the favorable position by tricking the opponent with the deceptive movement that one player should tempt the defensive player into moving off the right defense position with all kinds of deceptive movements and quickly seize the favorable position for grabbing the rebound when grabbing the offensive rebound. The third mean is taking place for grabbing the rebound. Taking place with force and direct grabbing are the important links of grabbing the offensive rebound.

Take-off Movement. It is the very important movement of grabbing the rebound to take off in time and fully extend the body. When one offensive player is grabbing the rebound, the take-off movement generally is used that he take off from his one foot, stare at the ball with his eyes, simultaneously swing his two arms and full extend them, exert the strength of abs and back coordinately to control balance of his body. When a player taking-off from his one foot, he should slightly back, let the weight transit from the rear foot to the front foot in the rolling way for taking-off and actively lift the swing leg for grabbing the rebound at the high point of a jump.

\section{The Major Problems Existed in Rebound Grabbing of Basketball Player}

Low Technical Level of Rebound Grabbing. Rebound technology play the key role in grabbing the rebound. One player with good rebound technology can grab more rebounds when the opportunities of grabbing the rebound is same with other players. Analysis results show that the major problems existed in rebound grabbing mainly include three aspects: less body confrontation when taking place and blocking the opponent, wrong take-off time and bad handling of the ball.

Lack of Rebound Consciousness and Judgement Ability for The Landing Point of The Rebound.The rebound consciousness is from the right judgement of the rebound direction and area of the basketball, and the mastering of the rebound rule of the rebound. But in a basketball match, in many cases, the player can not make the right judgement for the landing point of the rebound and grabbing the rebound with the advantages from his technology and position.

\section{Cultivation Method of Rebound Consciousness}

Strengthening the Training of Observation and Judgement. The player must exactly observe the space, position and distance through sight firstly, and then quickly make the right judgement for the stations and running path of the players and the arc, height, landing point and rebound point of the ball through his brain, and then run, block, turn-back or run parallel to the baseline for grabbing the rebound. After one player, the opponent or teammate shot, he should quickly observe the movements of the players, then carry out effective actions blocking the moving route of the 
opponent, running parallel to the baseline, grabbing the rebound by seizing the favorable position, making the basketball fly to his teammate for the second attack or organizing the quick attack.

Strengthening the Training of Basic Skill Basketball Technology. Strong basic skill is the prerequisite of successfully grabbing the rebound. The individual skill of grabbing the rebound is composed of the four parts taking place, take-off, getting the ball in the air and protecting the ball after landing which must be related closely. In addition, the four "must" should be carried out: must take place in time, must take-off on time, must exactly get the ball and must stably land. The player must cultivate the consciousness of grabbing the rebound for each shot (includes own shot). When one player or his teammate will shot, firstly, he should make the right judgement for the landing point of the ball, and get rid of the defensive player's block with his body's deceptive movements, and then take the place ahead or side ahead of the opponent by rounding, crossing or pushing through to seize the favorable position, and then carry out the rebound shot by taking off from standing position or taking off with approach face to the backboard, or organize the second attack after grabbing the rebound.

Cultivating the Rebound Consciousness Through the Mental Training and the Volitional Quality Training.

Psychic quality is a kind of expression of the reflect of the player's perception, knowledge, thinking and judgement in the practical action. A match is not only the skills and tactics competition, but also the psychic quality of the player. The psychic quality of young players is poorer, and they would have stress. The players often have the minds of being afraid of grabbing the rebound or even being willing to grab the rebound due to the senses of stress and timidity when their opponents are higher and stronger than them in the process of grabbing the rebound. So the mental training for the young players is required. In a match, the skills, tatics and psychic quality of one player should fully coordinate with the power and intelligence of the whole team to win the match. However, the players should gracefully win and lose a match, and improve their rebound consciousness with a normal psychological state in a match.

\section{Conclusion}

The control force of the defensive rebound should be strengthened. At the same time of enjoying the height advantage, the training of continual jump, upper and lower extremity strength and the flexibility of hands should also be strengthened to improve the ability of deflecting ball; the training of grabbing the rebound in confrontation should be strengthened; the right block place concepts should be established, and the training of block place technology should be strengthened; the control area of the rebound should be extended to grab more rebounds in the peripheral area. The important factors of grabbing the rebound are as follows:

pay more attention to the cultivation of the subjective initiative and the desire of grabbing the rebound of the player in daily training to make the player to actively grab the rebound. The mind level of the player is also the key factor for the formation of the rebound consciousness of player. So the training of the player's mind and intelligence should be strengthened. The rebound consciousness is the key of grabbing the rebound, and good physical fitness is the important base of rebound grabbing. Only all aspects of practice, the rebound grabbing ability of player can be radically improved.

\section{References}

[1] Kroon T, Kjellstedt A, Thalén P, et al. Dosing profile profoundly influences nicotinic acid's ability to improve metabolic control in rats.[J]. Journal of Lipid Research, 2015, 56(9):1679-90.

[2] Dykstra S, Engbers J D, Bartoletti T M, et al. Determinants of rebound burst responses in rat cerebellar nuclear neurons to physiological stimuli[J]. Journal of Physiology, 2016, 594(4):985-1003.

[3] Boettner B. Neutralizing HIV rebound[J]. SciBX: Science-Business eXchange, 2014, 7(36). 
[4] Nagornov R, Osipov G, Komarov M, et al. Mixed mode synchronization and network bursting of neurons with post-inhibitory rebound[J]. Physics, 2014.

[5] Todd M. Using compression hosiery to prevent rebound swelling.[J]. British Journal of Community Nursing, 2015, 20(Sup10):S20-S25.

[6] Han B, Yao S, Yu S, et al. Key Factors Affecting Pumpability,Strength and Rebound Rate of Wet Shotcrete[J]. Metal Mine, 2014.

[7] Shelton C M. Rebound Hardness Results For Raw Material, Located Near Pinnacle Point, South Africa And The Implications Thereof[J]. Journal of Physics B Atomic Molecular \& Optical Physics, 2015, 30(6):1589.

[8] Iizuka K, Takehana E, Nagasawa H. Colored golf ball: US, US8864605[P]. 2014.

[9] Dickinson H, Freed A M. Inferring Mantle Reology in Western Nevada Using Postseismic Relaxation and Lake Lahontan Rebound[C]// AGU Fall Meeting. AGU Fall Meeting Abstracts, 2014.

[10]Lehman J, Miikkulainen R. Extinction Events Can Accelerate Evolution[J]. Plos One, 2015, 10(8):e0132886.

[11] Koenig M K, Meyer K A, Kozfkay J R, et al. Evaluating the ability of tiger muskellunge to eradicate Brook Trout in Idaho alpine lakes.[J]. North American Journal of Fisheries Management, 2015, 35(4):659-670.

[12 Tanisho K, Ikarugi H, Yano T, et al. A longitudinal study of sprinting and agility in children, a case of junior athletes in a talent identification and development program[J]. 2017. 